\title{
Selective RNA Amplification: A Novel Method Using dUMP-containing Primers and Uracil DNA Glycosylase
}

\author{
George W. Buchman, David M. Schuster, and Ayoub Rashtchian
}

Life Technologies, Inc., Gibco/BRL, Gaithersburg, Maryland 20884-9980

The application of PCR to a wide variety of biological problems and molecular techniques has gained wide acceptance. RNA-PCR, a technique in which first-strand CDNA synthesis is followed by PCR amplification, has enabled detection and characterization of rare transcripts. One problem confronting the researcher involves specific amplification of transcribed sequences in the presence of small amounts of genomic DNA of identical sequence. We describe a novel technique, selective RNA amplification, which will specifically amplify RNA sequences in a background of homologous DNA. The method involves first-strand CDNA synthesis from a specific dUMP-containing oligonucleotide that contains unique userdefined $5^{\prime}$ sequence (adapter sequence) not found in the message of interest. RNA template is degraded using RNase $H$, which is specific for RNA/DNA hybrids. This is followed by second-strand synthesis using a gene-specific primer (GSP). The original adapter primer is digested with uracil DNA glycosylase (UDC) to prevent its participation in subsequent amplification. PCR is then performed using the GSP and a second primer corresponding to the unique adapter sequence. In this paper, we apply this method to the amplification of RNA derived from human papilloma virus sequences. Using Southern analysis, we demonstrate specific amplification of $10^{5}$ molecules of an in vitrotranscribed RNA. Denatured DNA of identical sequence and concentration was not amplified using the RNA-specific method. The method could eliminate the need for stringent purification of RNA and enables amplification of rare messages from RNA preparations containing homologous DNA of identical sequence and size.

$p$ CR has been widely used to study gene expression by amplification from RNA sequences. This approach requires conversion of the mRNA template to cDNA by reverse trancription (RT). ${ }^{(1,2)}$ To study the expression of genes it is important to selectively amplify RNA rather than DNA. One common method enabling differentiation between RNA and DNA employs primers that span the splice junctions in the RNA. This method is restricted to those RNA species that are spliced and imposes strict limitations on the design of amplification primers. The technique also requires substantial sequence information and knowledge of splice junctions. It is also possible to design primers that span an intron, which results in different size amplification products from spliced RNA and the genomic DNA with intron. This approach is, however, limited to the genes with introns and is not applicable to all genes, the bacterial transcripts, or the processed pseudogenes. ${ }^{(3)}$ Using a different method, Moore and co-workers ${ }^{(4)}$ have designed primers to the junction of the 3 ' untranslated sequence and the poly(A) tract. Although this method is generally applicable, it requires that the $3^{\prime}$-untranslated sequence of the mRNA be known and limits amplification to the $3^{\prime}$ region of the mRNA. In this report we describe a novel method for selective amplification from RNA over DNA. The method utilizes a dU-containing oligonucleotide as an adapter primer for firststrand synthesis on RNA. This primer contains a unique "adapter" nucleotide sequence at its 5 ' end that is not found in either the DNA or RNA. The introduction of new sequences into CDNA generated from RNA and not DNA allows selective amplification of RNA. After RT copies the sequence into second-strand cDNA, the original adapter primer is destroyed using uracil DNA glycosylase (UDG). The method is applicable to any RNA and permits amplification of any user-defined region within the RNA molecule.

\section{MATERIALS AND METHODS}

\section{Enzymes and Reagents}

Native Taq DNA polymerase was from Perkin-Elmer (Norwalk, CT). Buffer components and all other enzymes were from GIBCO BRL (Gaithersburg, MD). dNTPs were from Pharmacia (Piscataway, $\mathrm{NJ}$ ), and actinomycin $\mathrm{D}$ was from Boehringer Mannheim (Indianapolis, IN).

\section{Oligonucleotides}

All oligonucleotides were synthesized with a model 380A synthesizer from Applied Biosystems, Inc., using standard phosphoramidite chemistry. The dUphosphoramidite for preparation of dUcontaining oligonucleotides was from GIBCO BRL. The dU-containing oligonucleotides were purified and stored in the same way as T-containing oligonucleotides. ${ }^{(5)}$ Primer sequences are summarized in Table 1. 
TABLE 1 Oligonucleotide Primers and Probe Employed in the Selective RNA Amplification Procedure

\begin{tabular}{ll}
\hline Adapter primer & $5^{\prime}$-ggg aga ccg gaa uuc ucc uuc aau ugc uga ugc agg uga c-3' \\
Amplification primer (X) & $5^{\prime}$-ggg aga ccg gaa ttc tcc-3' \\
Gene-specific amplification & \\
$\quad$ primer (A) & $5^{\prime}$-ctg cat gat aat ata tgt ttg tgc g-3' \\
Probe oligonucleotide & $5^{\prime}$-tca gat gtc tct ttg gct gcc tag tga ggc cac tgt cta ctt gcc tcc tgt-3' \\
\hline
\end{tabular}

\section{RNA Preparation}

A DNA segment from the L1 region of human papilloma virus type 16 (HPV16) was cloned into plasmid vector pT7-12 (BRL) downstream from T7 RNA polymerase promoter. In vitro transcription was performed in a $1-\mathrm{ml}$ reaction using T7 RNA polymerase (BRL, 12,000 units), $10 \mu \mathrm{g}$ of linearized plasmid template DNA, inorganic pyrophosphatase (ICN, 25 units), human placental RNase inhibitor (200 units), $2 \mathrm{mM}$ rNTPs, $8 \mathrm{~mm}$ $\mathrm{MgCl}_{2}, 75 \mathrm{~mm} \mathrm{NaCl}, 20 \mathrm{~mm}$ Tris- $\mathrm{HCl}(\mathrm{pH}$ $8.0)$, and $100 \mu \mathrm{g} / \mathrm{ml}$ of BSA. The reaction was incubated for $60 \mathrm{~min}$ at $37^{\circ} \mathrm{C}$, and then phenol/chloroform extracted. DNA template was degraded using RNase-free DNase (GIBCO BRL). The RNA transcript was purified by Sephadex G-50 (Pharmacia) size-exclusion column chromatography. Equilibration and elution buffer was TE containing $100 \mathrm{mM} \mathrm{NaCl}$ and $0.1 \%$ SDS. Quantitation of nucleic acids was by spectrophotometric determination.

\section{CDNA Synthesis}

First-strand cDNA synthesis was performed according to instructions provided with the GIBCO BRL Superscript Preamplification System. A $20-\mu l$ reaction of the following composition was prepared: $20 \mathrm{~mm}$ Tris- $\mathrm{HCl}(\mathrm{pH} \mathrm{8.4}), 50$ mM KCl, $2.5 \mathrm{~mm} \mathrm{MgCl}_{2}, 100 \mu \mathrm{g} / \mathrm{ml}$ of BSA, $10 \mathrm{~mm}$ DTT, $1 \mu \mathrm{g} / \mathrm{ml}$ of actinomycin D, $500 \mu \mathrm{M}$ dNTPs, $500 \mathrm{nM}$ adapter primer, and $10 \mathrm{U} / \mu \mathrm{l}$ of Superscript RT (GIBCO BRL). RNA input varied from $10^{3}$ to $10^{8}$ copies of a 766 -base in vitro transcript prepared from a T7 promoter using a sequence derived from HPV16. The reaction was incubated for $20 \mathrm{~min}$ at $42^{\circ} \mathrm{C}$ and then removed to ice. The RNA template was degraded by the addition of 1 unit of RNase $\mathrm{H}$ to the first-strand reaction. Incubation was for $10 \mathrm{~min}$ at $42^{\circ} \mathrm{C}$. Second-strand synthesis was performed by the addition of 10 pmoles ( 1 $\mu \mathrm{l}$ of $10 \mathrm{pmoles} / \mu \mathrm{l})$ of the gene-specific primer (GSP) to the RNase H-treated first-strand synthesis reaction. Samples were incubated for $20 \mathrm{~min}$ at $42^{\circ} \mathrm{C}$. The original dUMP-containing adapter primer (both extended and nonextended) was degraded by the addition of 1 unit of UDG (GIBCO/BRL), followed by a 10 -min incubation at $42^{\circ} \mathrm{C}$.

\section{DNA Amplification by PCR}

In vitro DNA amplification was performed in $100 \mu \mathrm{l}$ final volume using a thermal cycler from Perkin-Elmer. Reagents were added to the entire UDGtreated reaction to yield the following final composition: $20 \mathrm{~mm}$ Tris- $\mathrm{HCl}(\mathrm{pH}$ 8.4), $50 \mathrm{~mm} \mathrm{KCl}, 2.5 \mathrm{~mm} \mathrm{MgCl}_{2}, 100 \mu \mathrm{g} /$ $\mathrm{ml}$ of BSA, $200 \mu \mathrm{M}$ dNTPs, $200 \mathrm{~nm}$ of each amplification primer, and 2 units of Taq DNA polymerase. The cycling profile was as follows: $5 \mathrm{~min}$ at $94^{\circ} \mathrm{C}, 30$ cycles of 1 $\min$ at $94^{\circ} \mathrm{C}, 1 \mathrm{~min}$ at $55^{\circ} \mathrm{C}, 2 \mathrm{~min}$ at $72^{\circ} \mathrm{C}$; and one final incubation at $72^{\circ} \mathrm{C}$ for $10 \mathrm{~min}$.

\section{Agarose Gel and Southern Blot Hybridization}

Products were analyzed by $2 \%$ agarose gel electrophoresis on a Horizon 58 minigel apparatus (BRL) at $16 \mathrm{~V} / \mathrm{cm}$ using a cooling fan, followed by ethidium bromide staining and UV fluorescence detection. Agarose gels were blotted to Biodyne B-charged nylon (Pall) according to instructions provided by the manufacturer. Hybridization using a $\left[{ }^{32} \mathrm{P}\right] 5^{\prime}$ end-labeled oligonucleotide probe $\left(1.8 \times 10^{8} \mathrm{dpm} / \mu \mathrm{g}\right)$ was at $45^{\circ} \mathrm{C}$ with a probe activity of $4 \times 10^{6} \mathrm{dpm} / \mathrm{ml}$. The hybridization buffer contained SDS (5\%), $1.0 \mathrm{M} \mathrm{NaCl}$, formamide (30\%), 1 mM Na ${ }_{2}$ EDTA, 50 mм NaH $\mathrm{PO}_{4}$ (pH 7.4), gelatin $(0.5 \%)$, and tRNA $(100 \mu \mathrm{g} / \mathrm{ml})$. Hybridization reactions were performed overnight and washed in $0.1 \times$ SSC containing $0.1 \%$ SDS at $45^{\circ} \mathrm{C}$.

\section{RESULTS AND DISCUSSION}

Selective RNA amplification is a tech- nique enabling specific amplification of a target RNA in a background of equimolar quantities of either single-stranded (ssDNA) or double-stranded (dsDNA) homologous DNA. The method utilizes a dUMP-containing adapter primer during first-strand cDNA synthesis to install a unique sequence that is not found in either the DNA or RNA copy (Fig. 1A). Both RNA and ssDNA may serve as templates for primer extension using the installation primer. Treatment with RNase $\mathrm{H}$ enables specific degradation of the RNA strand of RNA-DNA heteroduplex which results from the first-strand cDNA reaction. DNA extension products are not a substrate for the reaction, enabling discrimination between sequences of RNA and DNA origin (Fig. 1B). The adapter sequence is then copied during secondstrand synthesis using the gene-specific primer (shown as $A$ in Fig. 1). Once the adapter sequence has been copied during second-strand cDNA synthesis, the installation primer is destroyed by the action of UDG and heat. Amplification is performed with the same gene-specific primer used for second-strand cDNA synthesis and a dTMP-containing primer corresponding to the adapter region (amplification primer, shown as X in Fig. 1).

The feasibility of amplifying RNA with the method shown in Figure 1 was tested using an RNA transcript coding the $\mathrm{L} 1$ region of the HPV16 genome. Different amounts of RNA ranging from $10^{3}$ to $10^{8}$ molecules were amplified using the RNA-specific protocol as well as the conventional RNA-PCR method. Comparison of the amplification products and amplification level showed comparable levels of amplification, and $10^{3}$ molecules of RNA could easily be amplified and detected by ethidium bromide staining of agarose gels. There was only slight (twofold) reduction in sensitivity in some experiments when the RNA-specific method was used (data not shown). This difference in sensitivity is not related to use of dU primers, as previous studies have shown dU primers to prime as efficiently as their T-containing counterparts. ${ }^{(5,6)}$ Control reactions in which either reverse transcriptase or RNase $\mathrm{H}$ were omitted gave no amplification product with either RNA or DNA (data not shown).

The requirement of UDG treatment in the RNA-specific amplification was tested using RNA and DNA templates. 
A
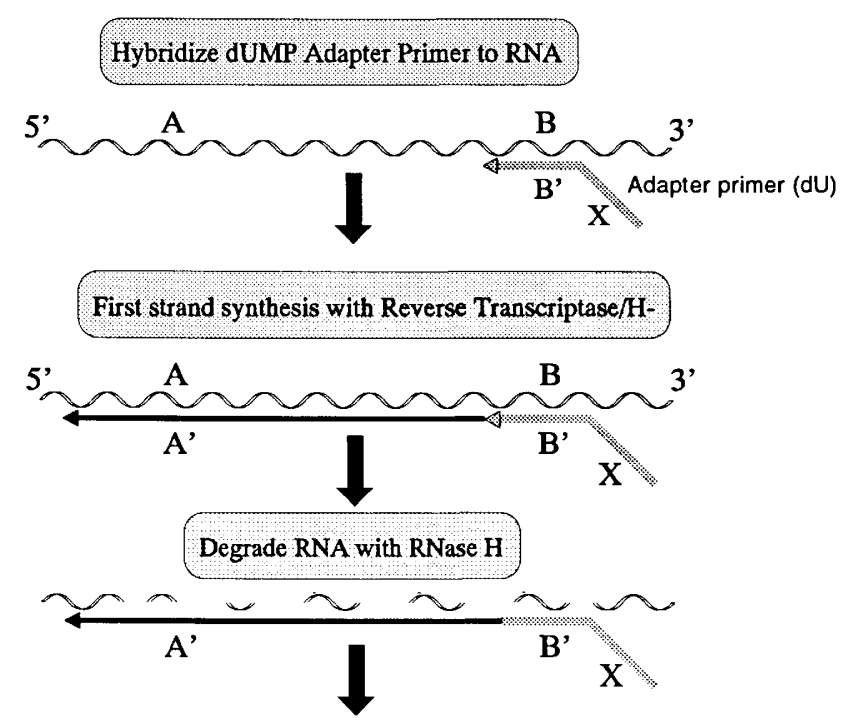

Hybridize Primer A / Second strand synthesis

Gene-specific primer
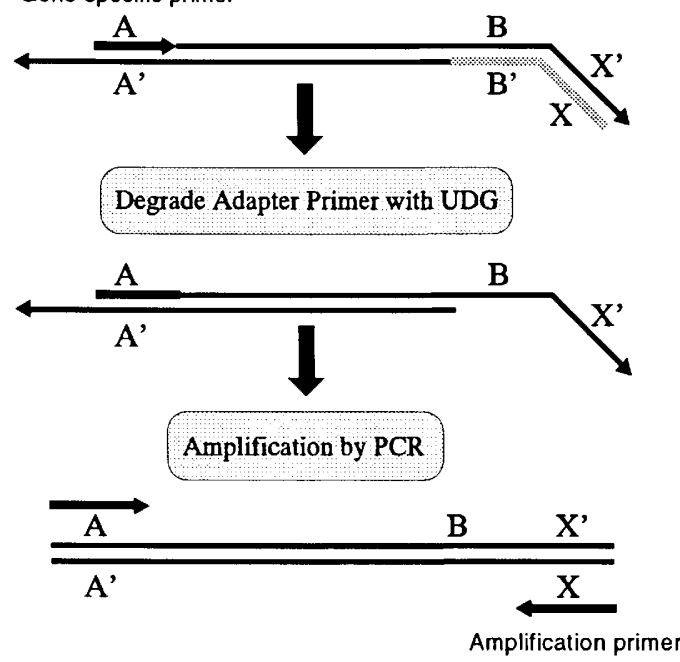

B

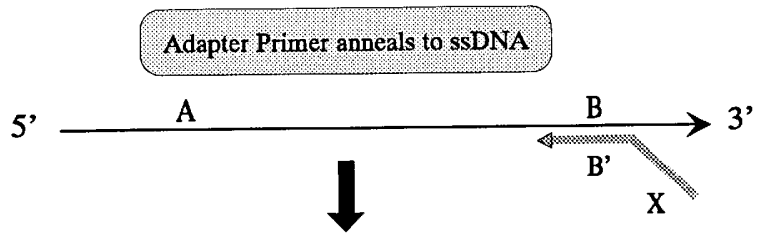

Primer extension using Reverse Transcriptase/H.
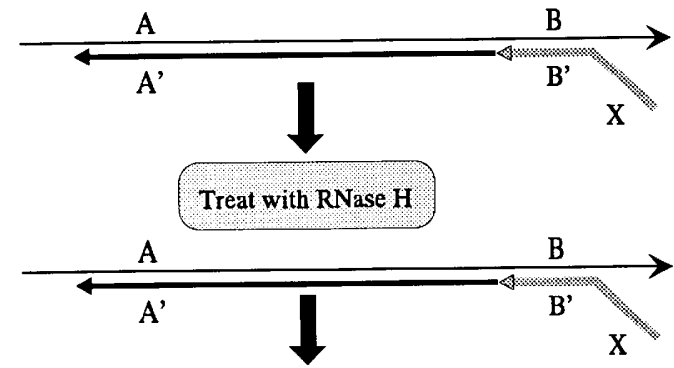

Add Primer A / No Second Strand Synthesis
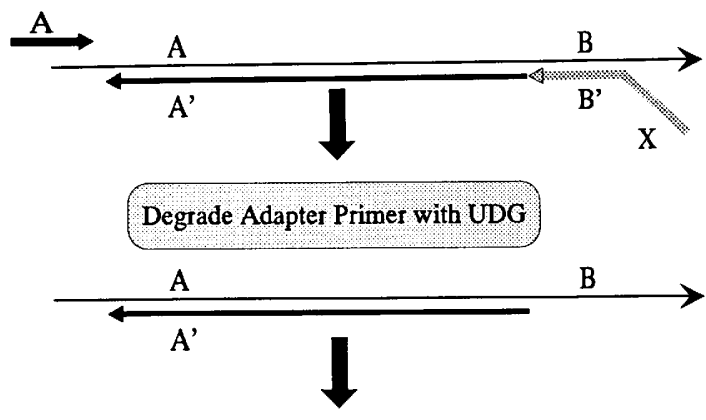

No Priming Site for Primer X/ No PCR Amplification

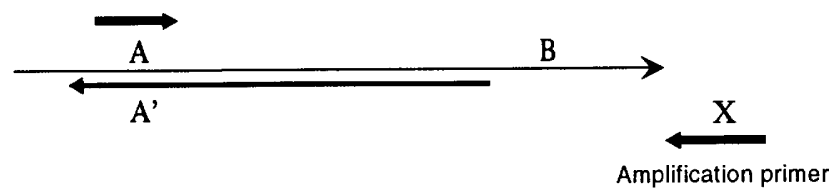

FIGURE 1 Schematic depiction of the strategy for selective amplification of RNA by PCR. $(A)$ Application of the method to RNA; $(B)$ the failure of ssDNA to amplify.

When the UDG treatment of the reaction mix was omitted, both RNA and DNA could be easily amplified with equal efficiency (Fig. 2). However, when the reaction products were treated with UDG before amplification, only the RNA templates were amplifiable (Fig. 3A). These experiments showed that UDG was essential for discrimination between RNA and DNA templates as predicted in the scheme. To show conclusively that DNA could not be amplified, the amplification products from these reactions were analyzed by hybridization of a ${ }^{32} \mathrm{P}$ labeled oligonucleotide probe to the blotted PCR products. Figure 3B shows that the amplification of DNA templates was prohibited using RNA-specific protocol, and the method was equally effective against double and ssDNA. Further experiments have shown that there is a $10^{3}$-fold discrimination between RNA and DNA when this method is used.

The use of PCR to study the expression of genes is now a common method. This approach is particularly useful when the amount of RNA to be analyzed is limited. Although a number of approaches have been proposed for selective amplification of RNA, their application is limited to only a subset of RNA species. $^{(4,7,8)}$ In this paper we have demonstrated that using an adapter primer in which the $\mathrm{T}$ residues have been sub- stituted with $\mathrm{dU}$, a specific sequence can be installed into RNA that allowed its selective amplification. The substitution of $T$ residues with dU allows specific removal of the adapter primer from the reaction mix simply by the addition of UDG. The other enzyme that plays a critical role in differentiation between RNA and DNA templates in this technique is RNase $H$. This enzyme removes the RNA strand from RNA-DNA hybrids resulting from RT of RNA templates, allowing selective amplification. The method is applicable to any RNA from variety of sources and does not rely on the splicing of the RNA or the specific structure of the $3^{\prime}$-untranslated region. 


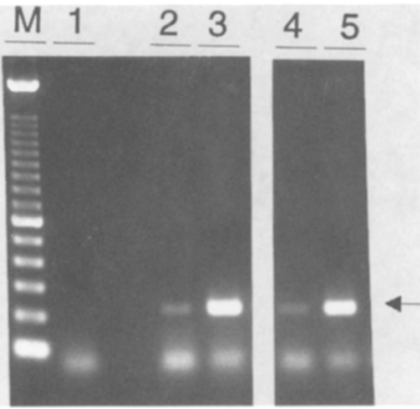

FIGURE 2 Amplification of RNA and DNA templates in the absence of UDG. cDNA synthesis and amplification were performed as shown in Materials and methods, except that the UDG treatment was omitted. Lane 1 contains all reagents except target RNA. Lanes 2 and 3 correspond to $10^{3}$ and $10^{5}$ original RNA molecule inputs into the first-strand reaction, respectively. Lanes 4 and 5 correspond to $10^{3}$ and $10^{5}$ molecules of denatured DNA, respectively. An aliquot of each reaction (5\%) was then analyzed by $2.5 \%$ agarose gel electrophoresis followed by ethidium bromide staining. Lane $M$ corresponds to the $100-\mathrm{bp}$ ladder (GIBCO/BRL).
The selective RNA amplification technique obviates the requirement for stringent purification of the RNA sample to be analyzed, including poly $(\mathrm{A})^{+}$selection and DNase treatment. This method should enable substantial reduction of false-positive PCR products derived from genomic copies of the RNA of interest. Recently methods for in situ amplification of RNA in fixed tissue specimens have been reported. ${ }^{(9,10)}$ The method described in this paper may be useful in specific amplification of RNA in samples of this type.

\section{REFERENCES}

1. Rappolee, D.A., D. Mark, M.J. Baanda, and Z. Werb. 1988. Wound macrophages express TGF-alpha and other growth factors in vivo: Analysis by mRNA phenotyping. Science 241: 708-710.

2. Kawasaki, E.S., S.S. Clark, M.Y. Coyne, S.D. Smith, R. Champlin, O.N. Witte, and F.P. McCormick. 1988. Diagnosis of chronic myeloid and acute lymphocytic leukemias by detection of leukemia-specific mRNA sequences amplified in vitro. Proc. Natl. Acad. Sci. 85: 5698-5702.

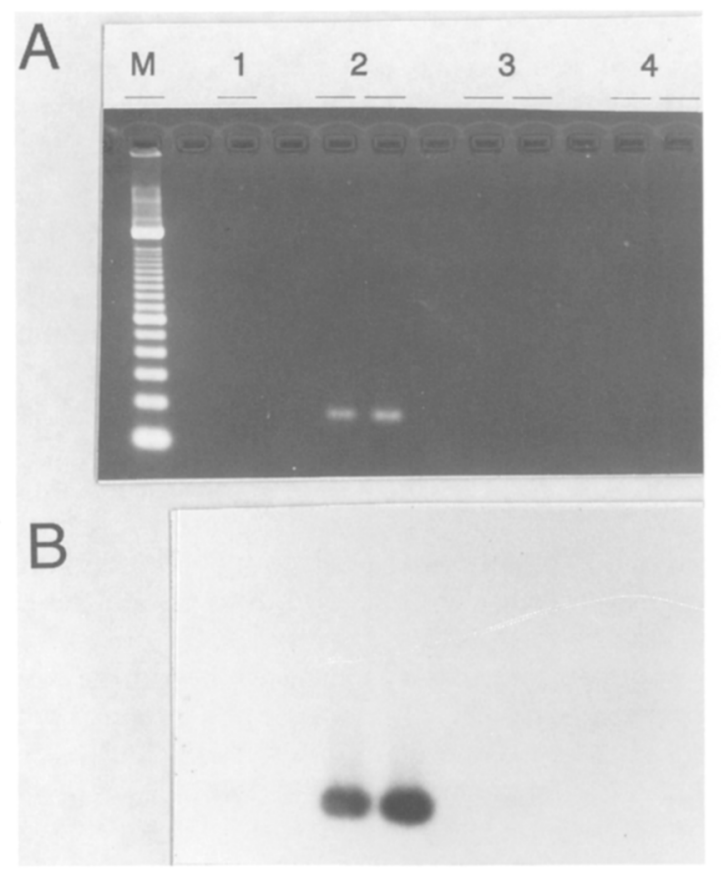

FIGURE 3 Selective RNA amplification. cDNA synthesis and amplification were performed as shown in Materials and Methods. In this case, UDG treatment was included to destroy the adapter primer. Lane 1 contains all reagents except target RNA. Lane 2 contains duplicate samples in which $10^{5}$ molecules of RNA were added to the cDNA reaction. Identical levels of denatured homologous DNA (lane 3, duplicate samples) or homologous duplex DNA (lane 4, duplicate samples) were also analyzed. $(A)$ A $2 \%$ ethidium bromide-stained agarose gel; $(B)$ the corresponding Southern analysis. An aliquot of each PCR reaction (10\%) was used for analysis. Lane $M$ corresponds to the 100-bp ladder (GIBCO/BRL). 


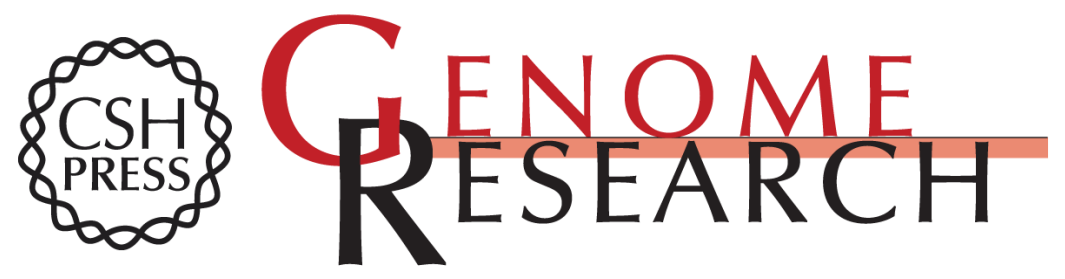

\section{Selective RNA amplification: a novel method using dUMP-containing primers and uracil DNA glycosylase.}

G W Buchman, D M Schuster and A Rashtchian

Genome Res. 1993 3: 28-31

References This article cites 9 articles, 2 of which can be accessed free at: http://genome.cshlp.org/content/3/1/28.full.html\#ref-list-1

License

Email Alerting

Receive free email alerts when new articles cite this article - sign up in the box at the Service top right corner of the article or click here.

\section{Affordable, Accurate Sequencing.}

To subscribe to Genome Research go to: https://genome.cshlp.org/subscriptions 